\title{
Entrapment of a laryngotracheal topical anesthesia kit during tracheobronchial foreign body removal: a case report
}

\author{
Xi-Yang Zhang ${ }^{1 *+} \mathbb{D}$, Yun Han ${ }^{2+}$, Ya-Bing Zhang ${ }^{3+}$, Ke-Xuan $\mathrm{Liu}^{1}$ and Bin $\mathrm{Liu}^{3}$
}

\begin{abstract}
Background: In order to reduce the irritation of the airway during tracheobronchial foreign body (TFB) removal, tracheal surface anesthesia is usually performed using a laryngotracheal topical anesthesia (LTA) kit (LTA20, Highgreen Medical Technology Company, China), but difficulty in withdrawing the LTA kit is rarely reported. We present a case of a difficulty to withdraw the LTA kit due to its entrapment by the movement of a TFB.

Case presentation: A 1-year-old girl was undergoing TFB removal. After the surgeon completed the tracheal surface anesthesia, the girl suddenly suffered from bucking, leading to the dislodgment of the TFB to the subglottic region, complicating the withdrawal of the LTA applicator. At the same time, the girl's oxygen saturation $\left(\mathrm{SpO}_{2}\right)$ decreased to 91\% and her heart rate dropped from 150 to $100 \mathrm{bpm}$. Atropine and succinylcholine were administered intravenously immediately, then the surgeon tried to free the TFB by pushing it back into the trachea, after which the LTA applicator was easily withdrawn, and TFB was removed successfully. The girl was discharged from hospital without any complications 2 days later.
\end{abstract}

Conclusion: This case report draws our attention to a significant anesthetic clinical consideration during the application of topical anesthesia on the trachea for TFB removal. The possibility of coughing or bucking can lead to migration of the TFB with subsequent airway obstruction, so the depth of anesthesia must be sufficient to prevent harmful reflexes. Also, strong teamwork and good communication are paramount to avoid serious complications.

Keywords: Child, Foreign body, Anesthesia, Airway

\section{Background}

TFB aspiration is a common life-threatening accident in children, especially those under age 4 [1]. Rigid tracheobronchoscopy is considered the gold standard technique for the management of TFB removal. Because of immature protective mechanisms and relatively narrow airways, severe complications, such as desaturation, laryngeal edema, bronchospasm, pneumothorax, pneumomediastinum, tracheal or bronchial laceration, and even cardiac arrest, can occur with attempting at TFB removal [2]. LTA applicator (LTA20, Highgreen Medical Technology Company, China) is usually used to perform

\footnotetext{
* Correspondence: zhangxiy17@163.com

${ }^{+}$Xi-Yang Zhang, Yun Han and Ya-Bing Zhang contributed equally to this work. 'Department of Anesthesiology, Nan Fang Hospital, Southern Medical University, Guangzhou, Guangdong, China

Full list of author information is available at the end of the article
}

tracheal surface anesthesia, so as to relieve the likelihood of a harmful reflex induced by rigid tracheobronchoscopy. To date, however, difficulties in withdrawing a LTA applicator due to its entrapment by movement of a $\mathrm{TFB}$, with the potential to lead to serious complications, has not been reported.

\section{Case presentation}

The patient's father provided written consent to the use the patient's medical information for research and publication.

A 1-year-old girl (weight $10 \mathrm{~kg}$ ) had suffered from a cough with sputum production for more than 2 days. She had a medical history of having swallowed a TFB 2 days earlier. The physical examination was normal, except for a wheezing sound in the right lung. A chest computed tomography scan revealed an $8 \times 4 \times 21 \mathrm{~mm}^{3}$

(c) The Author(s). 2018 Open Access This article is distributed under the terms of the Creative Commons Attribution 4.0 International License (http://creativecommons.org/licenses/by/4.0/), which permits unrestricted use, distribution, and 
mass in the trachea near the carina, which given the patient's history, was suggestive of the diagnosis of a TFB aspiration. After careful preoperative preparation, we scheduled the patient to undergo an emergency rigid tracheobronchoscopy to remove the TFB under general anesthesia. In order to keep the patient in spontaneous breathing, the combination of intravenous and inhalant anesthesia with propofol, fentanyl, and sevoflurane was planned to be administered. In the operating room, standard monitoring was installed, including $\mathrm{SpO}_{2}$, noninvasive blood pressure, and an electrocardiogram. Before administration of anesthesia, the child was premedicated with atropine $(0.1 \mathrm{mg})$ and dexamethasone (2 mg)intravenously. Then anesthesia induction was performed with $8 \%$ sevoflurane carried by $6 \mathrm{~L} / \mathrm{min}$ oxygen flow. After the patient became unconscious, anesthesia was maintained with $3-5 \%$ sevoflurane and $1 \mathrm{~L} / \mathrm{min}$ oxygen flow for more than $5 \mathrm{~min}$. Before rigid tracheobronchoscopy introduced into the trachea, the child received propofol $(20 \mathrm{mg})$ and fentanyl $(10 \mu \mathrm{g})$ intravenously to deepen the anesthesia. After 1-2 min, when her lower jaw was flabby, the surgeon introduced a LTA applicator into the trachea under the guidance of rigid tracheobronchoscopy, and then sprayed topical 1\% lidocaine on the surfaces of the vocal cords and trachea. After the surgeon applied the topical anesthetic to the trachea, the girl suddenly suffered from bucking, which made it difficult to withdraw the LTA applicator. The surgeon quickly examined the opening of the main trachea using rigid tracheobronchoscopy, and found the TFB had migrated to the subglottic region against the LTA applicator. In this situation, manual ventilation became impossible and within half a minute, the patient's $\mathrm{SpO}_{2}$ decreased to $91 \%$ and her heart rate dropped from 150 to $100 \mathrm{bpm}$. We administered an intravenous injection of atropine $(0.3 \mathrm{mg})$ and succinylcholine $(10 \mathrm{mg})$. Meanwhile, the surgeon tried to free the TFB by pushing it back into the trachea, after which the LTA kit was easily withdrawn. We then mask-ventilated the lungs successfully. The patient's $\mathrm{SpO}_{2}$ quickly increased to $97 \%$ and her heart rate rose to $140 \mathrm{bpm}$. After deepening the anesthesia with propofol $(20 \mathrm{mg})$ intravenously, the surgeon successfully grabbed and removed the TFB under jet ventilation (Fig. 1). Afterwards, the girl's condition improved quickly and she recovered uneventfully. She was discharged from the hospital 2 days later without complications.

\section{Discussion and conclusions}

There are 2 primary ventilatory models for guiding anesthetic management during TFB removal: spontaneous respiration and controlled ventilation [3]. Generally, the use of spontaneous respiration without a muscle relaxant provides continuous ventilation, and may not

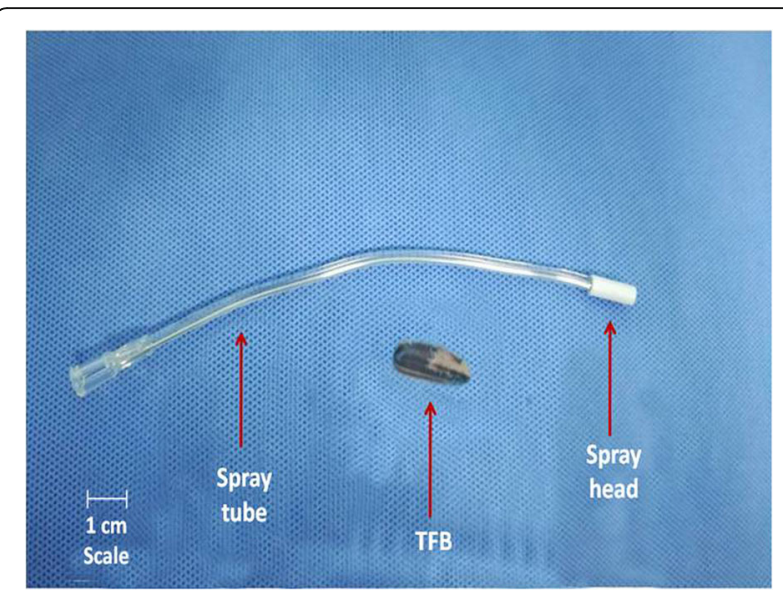

Fig. 1 Laryngotracheal topical anesthesia (LTA) kit and tracheobronchial foreign body (TFB)

result in complete airway obstruction. However, when using this technique, the anesthetist is challenged to maintain the anesthetic depth, and they usually add topical anesthesia to suppress airway reflexes. The use of controlled ventilation with a muscle relaxant may facilitate the avoidance of patient coughing and bucking, and facilitate the extraction of a TFB, but this technique has some potential risks, such as barotrauma and dislodgment of the foreign body, especially when using jet ventilation through a thin catheter.

The retrospective study of Chai et al. suggests that applying topical lidocaine to the oropharynx, glottic structures, or the subglottic region is helpful and reduces the amount of anesthetics needed to remove a TFB [4], but existing data on the effectiveness of this technique remains mixed [5]. Although our hospital commonly uses a LTA kit to carry out tracheal surface anesthesia, the use of topical lidocaine anesthesia may sometimes result in adverse events, such as bucking, breath holding, laryngospasm, and body movement. We report a rare, but potentially serious incident of an LTA applicator becoming entrapped by a TFB.

In our case, the LTA kit together with the TFB almost completely blocked the subglottic region, leading to a potentially life-threatening situation. We speculate that the cause for this obstruction was inadequate anesthesia depth. We used general anesthesia with spontaneous respiration, so the anesthesia was not deep enough to prevent harmful reflexes to the topical lidocaine spray, such as bucking and body movement. These reflexes resulted in the movement of the TFB and airway obstruction.

The complication rates associated with controlled ventilation vs. spontaneous respiration are similar, except for lower incidence of laryngospasm when controlled ventilation is performed [3]. In our case, the surgeon 
was able to extract the LTA kit after the administration of succinylcholine; nevertheless, attention should be paid to the possibility of complete airway obstruction when surgeons prepare for such procedure. In another reported case, a foreign body was lodged in the subglottic region, but unlike us, the surgeon successfully removed the seed in pieces without using succinylcholine [6].

As reported, strong teamwork, especially good communication between the medical care providers, is vital to the improvement of patient outcome, the prevention of potentially avoidable complications, and thus the reduction of morbidity and mortality [7]. Therefore, as for the enhanced intraoperative management in our case, we thought that frequent communication between the anesthesiologist and the surgeon throughout the case was extremely important, as insertion of rigid tracheobronchoscopy, spraying topical $1 \%$ lidocaine, clamping of the TFB, and other stimulation required to maintain sufficient anesthetic depth.

In a word, we present a case of a difficulty withdrawing a LTA applicator during attempted TFB removal. This case report highlights an important clinical anesthetic consideration when applying topical anesthesia on the trachea for TFB removal. Anesthesia providers should be prepared for the possibility of coughing and bucking, leading to migration of the TFB with subsequent airway obstruction. This situation may possibly be avoided by ensuring an adequate depth of anesthesia prior to the application of lidocaine to the trachea that relieves airway reflexes. Also, facing the event of airway obstruction, preparedness and team communication are paramount to avoid serious complications.

\section{Abbreviations}

LTA: Laryngotracheal topical anesthesia; $\mathrm{SpO}_{2}$ : Oxygen saturation;

TFB: Tracheobronchial foreign body

\section{Funding}

This work was financially supported by the President Foundation of Nanfang Hospital, Southern Medical University (No. 2017C014, to Dr. Xiyang Zhang) and the National Natural Science Foundation of China (No. 81671955, to Dr Kexuan Liu), but the funding bodies did not play any roles in the design of the study and collection, analysis, and interpretation of data and in writing the manuscript.

\section{Availability of data and materials}

All data and materials described in the manuscript will be freely available to any scientist wishing to use them for non-commercial purposes.

\section{Authors' contributions}

$Z X Y, H Y$ and $Z Y B$ contributed equally to this paper. $Z X Y$ and $H Y$ were responsible for preparation of the manuscript; $Z Y B$ was in charge of collecting the date of patient; LB participated in patient care; LKX involved in the case and drafted the manuscript. All authors read and approved the final manuscript.

\section{Consent for publication}

Written informed consent was obtained from the patient's father for publication of this case report. A copy of the written consent is available for review by the Editor of this journal.

\section{Competing interests}

The authors declare that they have no competing interests.

\section{Publisher's Note}

Springer Nature remains neutral with regard to jurisdictional claims in published maps and institutional affiliations.

\section{Author details \\ 'Department of Anesthesiology, Nan Fang Hospital, Southern Medical University, Guangzhou, Guangdong, China. ${ }^{2}$ The First Clinical Medical College, Southern Medical University, Guangzhou, China. ${ }^{3}$ Department of Anesthesiology, West China Hospital of Sichuan University, Chengdu, China.}

Received: 8 January 2018 Accepted: 25 May 2018

Published online: 01 June 2018

References

1. Fidkowski CW, Zheng H, Firth PG. The anesthetic considerations of tracheobronchial foreign bodies in children: a literature review of 12,979 cases. Anesth Analg. 2010;111(4):1016-25.

2. Wen WP, Su ZZ, Wang ZF, Zhang JJ, Zhu XL, Chai LP, Feng X, Liu KX, Jiang AY, Lei WB. Anesthesia for tracheobronchial foreign bodies removal via selfretaining lanyngoscopy and Hopkins telescopy in children. Eur Arch Otorhinolanyngol. 2012;269(3):911-6

3. Liu Y, Chen L, Li S. Controlled ventilation or spontaneous respiration in anesthesia for tracheobronchial foreign body removal: a meta-analysis. Paediatr Anaesth. 2014;24(10):1023-30.

4. Chai J, Wu XY, Han N, Wang LY, Chen WM. A retrospective study of anesthesia during rigid bronchoscopy for airway foreign body removal in children: propofol and sevoflurane with spontaneous ventilation. Paediatr Anaesth. 2014;24(10):1031-6.

5. Roberts $\mathrm{MH}$, Gildersleve $\mathrm{CD}$. Lignocaine topicalization of the pediatric airway. Paediatr Anaesth. 2016;26(4):337-44.

6. Kumar S, Saxena AK, Kumar M, Rautela RS, Gupta N, Goyal A. Anesthetic management during bronchoscopic removal of a unique, friable foreign body. Anesth Analg. 2006;103(6):1596-7.

7. Kumar M, Dash HH, Chawla R. Communication skills of anesthesiologists: an Indian perspective. J Anaesthesiol Clin Pharmacol. 2013;29(3):372-6.

\section{Ready to submit your research? Choose BMC and benefit from:}

- fast, convenient online submission

- thorough peer review by experienced researchers in your field

- rapid publication on acceptance

- support for research data, including large and complex data types

- gold Open Access which fosters wider collaboration and increased citations

- maximum visibility for your research: over 100M website views per year

At BMC, research is always in progress.

Learn more biomedcentral.com/submissions 